\title{
LA-UR- $9 \%-1288$ \\ Titte: On the Influence of Dispersoids on the Particle Stimulated Nucleation of Recrystallization in an Al-Fe-Si Model Alloy
}

Author(s):

O. Engler, CMS

RECEIVED

FFR 021998

OSTI

International Conference On Textures and Anisotropy of

Polycrystals,

9/22-25/97

Claushal, Germany

\section{6}

\section{Los Alamos}

\section{NATIONAL LABORATORY}

Los Alamos National Laboratory, an affirmative action/equal opportunity employer, is operated by the University of California for the U.S. Department of Energy under contract W-7405-ENG-36. By acceptance of this article, the publisher recognizes that the U.S. Govemment retains a nonexclusive, royalty-free license to publish or reproduce the published form of this contribution, or to allow others to do so, for U.S. Government purposes. The Los Alamos National Laboratory requests that the publisher identify this article as work performed under the auspices of the U.S. Department of Energy. 


\section{DISCLAIMER}

This report was prepared as an account of work sponsored by an agency of the United States Government. Neither the United States Government nor any agency thereof, nor any of their employees, makes any warranty, express or implied, or assumes any legal liability or responsibility for the accuracy, completeness, or usefulness of any information, apparatus, product, or process disclosed, or represents that its use would not infringe privately owned rights. Reference herein to any specific commercial product, process, or service by trade name, trademark, manufacturer, or otherwise does not necessarily constitute or imply its endorsement, recommendation, or favoring by the United States Government or any agency thereof. The views and opinions of authors expressed herein do not necessarily state or reflect those of the United States Government or any agency thereof. 


\title{
On the Influence of Dispersoids on the Particle Stimulated Nucleation of Recrystallization in an Al-Fe-Si Model Alloy
}

\author{
O. Engler \\ Los Alamos National Laboratory, Center for Materials Science, K765, Los Alamos, \\ NM 87545, USA
}

Keywords: recrystallization, nucleation, particle stimulated nucleation (PSN), dispersoids, EBSD

\begin{abstract}
The recrystallization of $\mathrm{Al}$-alloys is controlled by precipitates. Whereas large particles generally promote recrystallization by particle stimulated nucleation, finely dispersed precipitates - either already present in the as-deformed state or precipitating during the recrystallization anneal-are known to strongly retard recrystallization. It was the aim of the present study to elucidate these concurring effects of large particles and small dispersoids on recrystallization in a ternary Al-Fe-Si model alloy. For that purpose, samples were prepared according to different pre-annealing treatments so as to comprise different states of precipitation and supersaturation. The evolution of microstructure and texture during rolling and recrystallization was characterized by metallography and by conventional X-ray texture analysis. EBSD-local texture investigations were employed to yield information on the efficiency of nucleation at the various nucleation sites and, consequently, on the influence of dispersoids on recrystallization.
\end{abstract}

\section{Introduction}

The recrystallization behavior of $\mathrm{Al}$-alloys is strongly affected by the precipitation state. Large particles $(>1 \mu \mathrm{m})$ are generally assumed to promote recrystallization by adding additional nucleation sites, which is usually referred to as particle stimulated nucleation (PSN) [1]. Small dispersoids, on the other hand, are known to strongly retain both recovery and recrystallization and, thus, they retard the progress of recrystallization $[2,3]$. In the presence of a bimodal particle distribution, a complex interaction between the large particles and the small dispersoids can occur. In addition, in the case of a supersaturation of solute atoms, new dispersoids may form which also affects the progress of recrystallization.

In recent studies on binary $\mathrm{Al}-1.8 \% \mathrm{Cu}[4]$ and on commercial $\mathrm{Al}-\mathrm{Mn}-\mathrm{Mg}$ alloys (AA3xxx) [5,6] it was observed that a precipitation of solutes on the deformed substructure occurring concurrently with recrystallization led to a cube-recrystallization texture. This effect was attributed to a selective pinning of PSN, while the cube-nuclei could grow and, hence, finally dominate the recrystallization textures. Annealing of the same samples at high temperatures where no precipitation occurred resulted in a fine grained microstructure and a more random texture, which indicated that PSN was most effective. Likewise, examinations of commercial Al-Mg-Si alloys (AA6xxx) [7,8] and $\mathrm{Al}-\mathrm{Si}$ model alloys $[9,10]$ proved that dispersoids which were already present prior to the final recrystallization anneal are also very efficient in inhibiting PSN. The present paper reviews recent results about the influence of the precipitation and supersaturation state on recrystallization in a high purity ternary Al-Fe-Si model alloy with $0.35 \mathrm{wt} \% \mathrm{Fe}$ and $0.7 \mathrm{wt} \% \mathrm{Si}[11]$ and presents new results on the spatial arrangement of the recrystallization texture orientations which were determined by electron backscattering diffraction (EBSD) in an SEM. 


\section{Sample Preparation and Experimental Procedures}

From a cast ingot made of a high purity $\mathrm{Al}-0.35 \mathrm{wt} \% \mathrm{Fe}-0.7 \mathrm{wt} \% \mathrm{Si}$ model alloy a $40 \mathrm{~mm}$ thick bar was prepared. In order to receive a homogeneous fine grained initial structure, the bar was cold rolled by $50 \%$ thickness reduction, annealed for $1 \mathrm{~h}$ at $550^{\circ} \mathrm{C}$, again rolled $50 \%$ and finally annealed for $30 \mathrm{~min}$ at $500^{\circ} \mathrm{C}$. This pre-treatment led to a recrystallized microstructure with an average grain size of $\sim 60 \mu \mathrm{m}$. To vary the state of supersaturation as well as precipitation prior to the final cold deformation process, three specimens prepared from this bar were subjected to different annealing treatments (cf. Tab. 1). The resulting precipitation state of the different materials was characterized by measurements of the electrical conductivity and the Vickers microhardness and, in particular, by means of quantitative metallography in an SEM. Some data on average particles size, spatial density and volume fraction are given in Tab. 1.

After the final anneal, one specimen, which in the following will be referred to as "Q", was immediately water quenched. In this material, a large number of Fe- and Si-containing constituent particles with size $>1 \mu \mathrm{m}$ were observed which in principle are able to initiate PSN (see below).

A second specimen, denoted "S", was slowly cooled within $12 \mathrm{~h}$ from the pre-annealing temperature, $500^{\circ} \mathrm{C}$, down to $250^{\circ} \mathrm{C}$. This treatment caused an increase in size and volume fraction of the constituent particles, whereas their spatial density remained more or less constant (Tab. 1). This means that mainly the already existing particles grew, rather than that new precipitates formed.

The third specimen, labeled "A", was water quenched after the $500^{\circ} \mathrm{C}$ anneal and then aged for $96 \mathrm{~h}$ at $250^{\circ} \mathrm{C}$ approximately to the same electrical conductivity as specimen "S", i.e. the same number of atoms retained in solute solution. In this sample, the size and the volume of the large constituent particles remained virtually unchanged with respect to the as-quenched state $Q$ but, in addition, a very high number of small dispersoids with an average size of less than $50 \mathrm{~nm}$ formed, so that a bimodal particle distribution was obtained (Tab. 1).

\begin{tabular}{|c|c|c|c|c|c|}
\hline \multicolumn{3}{|l|}{ Specimen } & $\mathbf{Q}$ & $\mathbf{S}$ & $\mathbf{A}$ \\
\hline \multicolumn{3}{|c|}{ Pre-Treatment } & $\begin{array}{l}\text { water } \\
\text { quenched }\end{array}$ & $\begin{array}{l}\text { slowly cooled } \\
\text { to } 250^{\circ} \mathrm{C}\end{array}$ & $\begin{array}{l}\text { annealed for } \\
96 \mathrm{~h} \text { at } 250^{\circ} \mathrm{C}\end{array}$ \\
\hline \multirow{3}{*}{ Properties } & \multicolumn{2}{|c|}{ el. conductivity $\sigma\left[\Omega \mathrm{m} / \mathrm{mm}^{2}\right]$} & 32.8 & 34.1 & 33.9 \\
\hline & \multicolumn{2}{|c|}{ microhardness [HV] } & 25 & 21 & 23 \\
\hline & \multicolumn{2}{|c|}{ grain size $[\mu \mathrm{m}]$} & 60 & 54 & 58 \\
\hline \multirow{5}{*}{$\begin{array}{l}\text { Particle } \\
\text { State }\end{array}$} & \multirow[t]{3}{*}{ large } & size $[\mu \mathrm{m}]$ & 2.0 & 2.5 & 2.1 \\
\hline & & density $\left[\mathrm{m}^{-2}\right]$ & $3.9 \cdot 10^{9}$ & $4.5 \cdot 10^{9}$ & $4.1 \cdot 10^{9}$ \\
\hline & & volume fraction [\%] & 2.0 & 4.5 & 1.8 \\
\hline & \multirow[t]{2}{*}{ small } & size $[\mu \mathrm{m}]$ & 1 & 1 & $<50 \mathrm{~nm}$ \\
\hline & & density $\left[\mathrm{m}^{-2}\right]$ & 1 & 1 & $>5 \cdot 10^{12}$ \\
\hline
\end{tabular}

Tab. 1: Characterization of the three different starting materials.

Subsequently, the three different specimens were cold rolled by $90 \%$ to $1 \mathrm{~mm}$ thick sheets and finally recrystallization annealed at various temperatures between 250 and $450^{\circ} \mathrm{C}$ in a salt bath. In addition to standard metallography, conventional X-ray texture analysis and measurements of microhardness and electrical conductivity, EBSD local texture analysis was employed to yield information on the orientation distribution of different grain size classes. More details on sample preparation and experimental procedures can be found in Ref. [11]. 


\section{Results and Discussion}

As already described in more detail in a preceding paper [11], the results obtained after complete recrystallization could basically be subdivided into two groups. In samples where recrystallization was not affected by dispersoids - i.e. in the equilibrium samples $S$ and the supersaturated samples $Q$ after annealing at high temperatures - very weak recrystallization textures were observed. Besides a high fraction of randomly oriented grains, a cube-orientation that is remarkably rotated about the normal direction (ND) towards $\{001\}<310>$ as well as the P-orientation $\{011\}<122>$ occurred (e.g. Fig. 1a). This texture type has frequently been associated with recrystallization being governed by PSN (e.g. $[4,5,12]$ ). In the microstructures of these samples very fine grained, equiaxed recrystallized grains with an average size of $<30 \mu \mathrm{m}$ were observed (Fig. 2a; Tab. 2). Thus, it is anticipated that in these samples the large constituent particles (Tab. 1) can act as viable nucleation sites for recrystallization.

In samples where dispersoids were to be expected - i.e. in the aged samples $A$ and the supersaturated samples $Q$ after recrystallization at low to medium temperatures - another texture type occurred. Here, the recrystallization textures mainly comprised the cube-orientation $\{001\}<100>$ with strong scatter about the rolling direction (RD) as well as the R-orientation $\{124\}<211>$ (Fig. 1b), which are the typical recrystallization texture components of Al-alloys in

\begin{tabular}{|l|l|l|l|}
\hline$T_{R}$ I Sample & "S" & "Q" & "A" \\
\hline $250^{\circ} \mathrm{C}$ & 25.6 & 39.9 & 52.0 \\
\hline $300^{\circ} \mathrm{C}$ & 31.8 & 40.4 & 38.8 \\
\hline $350^{\circ} \mathrm{C}$ & 27.0 & 34.8 & 35.6 \\
\hline $\mathbf{4 5 0 ^ { \circ } \mathrm { C }}$ & 27.9 & 27.0 & 39.1 \\
\hline
\end{tabular}

Tab. 2: Grain size after recrystallization of the various samples [ $\mu \mathrm{m}]$. the absence of PSN (e.g. [12-16]). It is known that this texture type is dominated by the nucleation of cube-oriented grains at the so-called cube-bands - band-like structures which are composed of cube-oriented subgrains which pre-exist in the as-deformed microstructure (e.g. $[12,15,16])$ - and by the nucleation of R-oriented grains at the large-angle grain boundaries in the as-deformed state [12]. Thus, in accordance with earlier investigations [4-11] it is concluded that the dispersoids which are either present already before the recrystallization (samples A) or form during the recrystallization anneal (samples Q) strongly inhibit PSN but affect nucleation of cube- and R-oriented

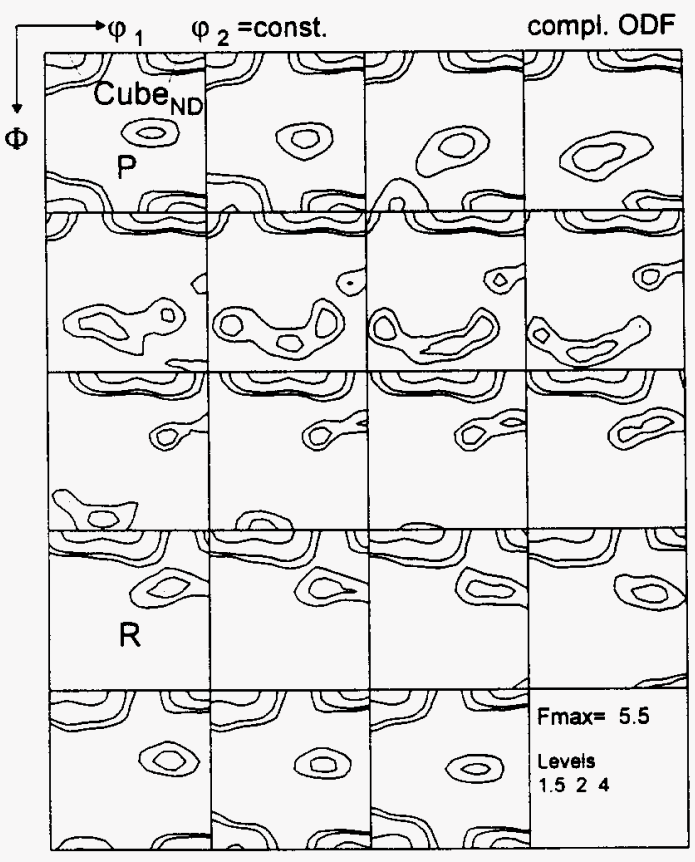

(a) sample "S", $T_{R}=450^{\circ} \mathrm{C}$

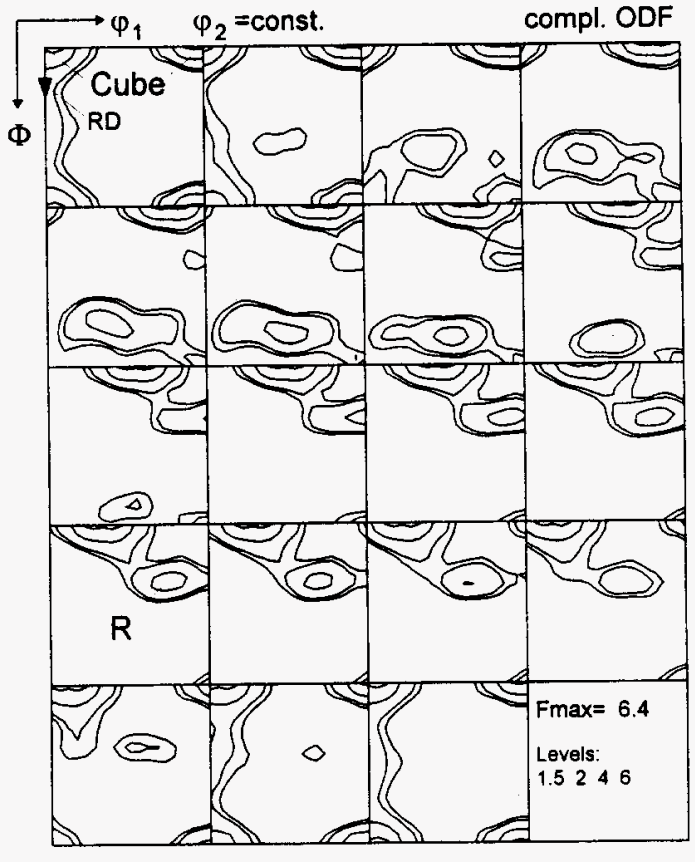

(b) sample " $A$ ", $T_{R}=350^{\circ} \mathrm{C}$

Fig. 1: Textures after complete recrystallization. 

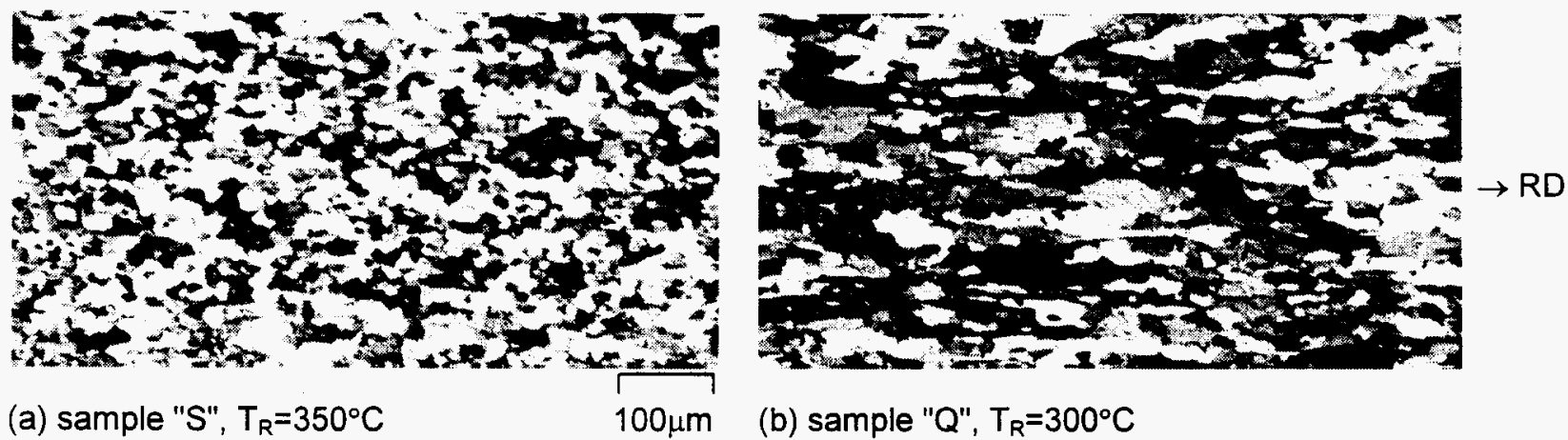

Fig. 2: Microstructure after complete recrystallization.

grains much less. This difference has repeatedly been attributed to the different geometrical features at the two nucleation sites [5-8,11]: The Zener-drag exerted by the dispersoids results in an increase in the critical size for successful nucleus growth. In case of PSN, the critical nucleus size can readily exceed the maximum size provided by the deformation zones, so that PSN can not longer take place. The subgrains in the cube-bands, in contrast, can more easily expand by subgrain growth or, possibly, by subgrain coalescence, until they exceed the critical nucleus size and, hence, the cubeorientation prevails in the presence of dispersoids. In comparison to the textures forming through PSN, it furthermore turned out that the cube-recrystallization textures were generally associated with larger, slightly elongated grains with an average size of $40 \mu \mathrm{m}$ (Fig. 2b; Tab. 2) and that recrystallization proceeded much slower [11]. These two observations also hint at the reduced nucleation conditions in the presence of dispersoids.

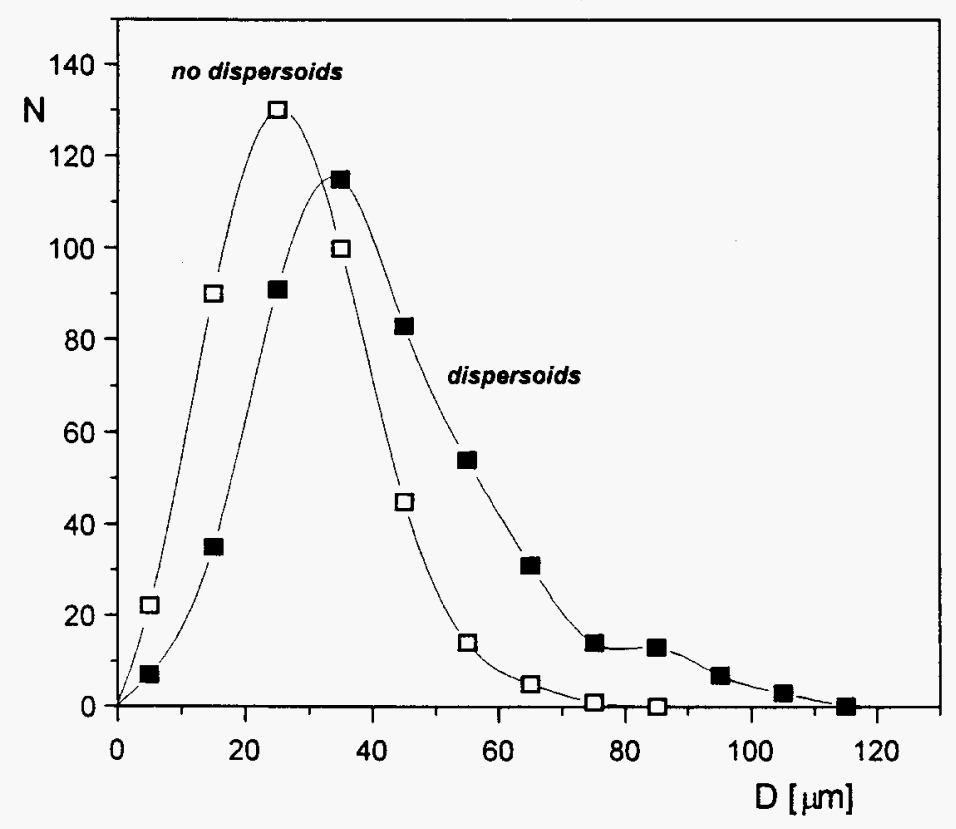

Fig. 3: Grain size distributions of the two different groups.

To analyze the differences in grain size in more detail, the grain size distributions of the two different groups were determined (Fig. 3). As already qualitatively stated above, in the samples recrystallizing in the absence of dispersoids, PSN leads to a homogeneous grain size distribution with an average grain size of about $25 \mu \mathrm{m}$. In the presence of dispersoids, however, the average grain size was slightly larger, about $35 \mu \mathrm{m}$, and, in particular, a more pronounced tail towards larger grain size data and even an indication for a bimodal grain size distribution appeared.

In order to check whether the various grain sizes are linked to the different recrystallization texture components and, thus, to the different nucleation sites, a recrystallized sample of material A was examined by EBSD local texture analysis. For that purpose, the electron beam in the SEM was controlled to scan a sampling area of about $1 \mathrm{~mm} \times 1 \mathrm{~mm}$ in steps of $3 \mu \mathrm{m}$, and for each point the crystallographic orientation was determined by EBSD. This technique which is commonly referred to as orientation imaging microscopy (OIM ${ }^{\mathrm{TM}}$ ) allows to reproduce the microstructure of a sample from the crystallographic orientations of the microstructural elements [17]. After some appropriate filtering operations, the recrystallized grains 
were defined as regions of contiguous, similarly oriented points with local misorientations below $15^{\circ}$. The grain size was then determined as the radius of a circle with the same area. Fig. 4 shows an orientation map in which the grains were shaded according to their sizes in three different grain size classes: Largest grains with a size $D$ exceeding $40 \mu \mathrm{m}$ are marked with white color and medium sized grains with $5 \mu \mathrm{m}<D<40 \mu \mathrm{m}$ with gray color. Smallest "grains" with a size below $5 \mu \mathrm{m}$, marked black, may actually represent points with wrongly indexed patterns or grain boundary regions and, therefore, they were omitted in the following. Finally, for each grain size class separate ODFs were calculated (Fig. 5) which could then be compared with the two typical recrystallization textures shown in Fig. 1. Other cut-off values were proved not to significantly alter the conclusions discussed in the following.

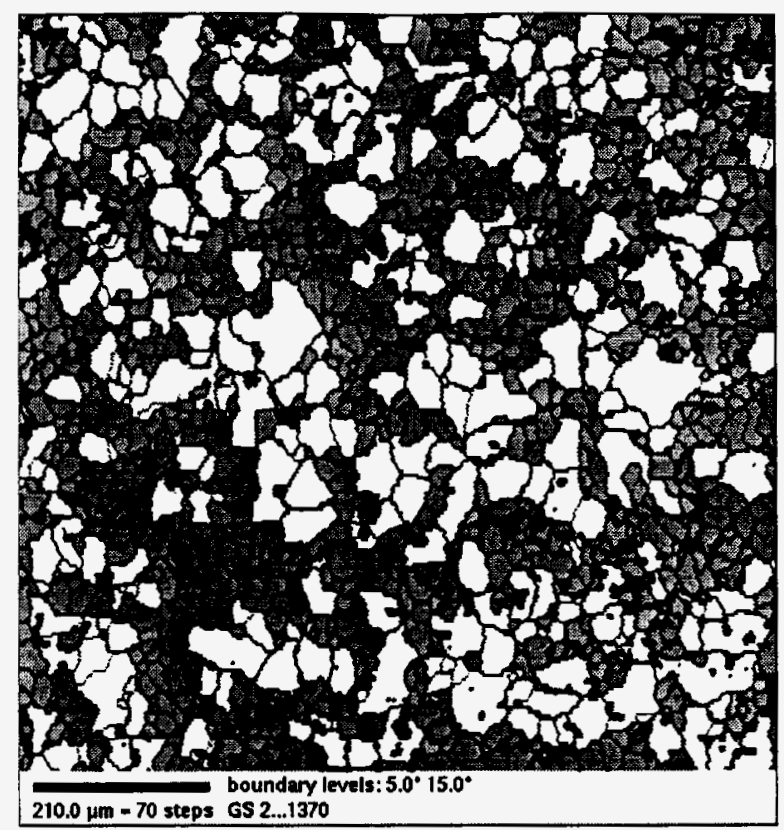

Fig. 4: EBSD-orientation map of sample $A$, shaded according to the grain size $\left(T_{R}=250^{\circ} \mathrm{C}\right)$

The orientation distribution of the large grains (Fig. 5a) comprises a pretty sharp cube-orientation, $f(g)_{\max }>6$, with pronounced $\mathrm{RD}$-scatter as well as some intensities of the R-orientations with some scatter towards the P-orientation. This ODF strongly resembles the recrystallization texture of the samples in the presence of dispersoids, where PSN is expected to be suppressed (e.g. Fig. 1b). This resemblance suggests that the large, successfully growing grains can be attributed to the cube-bands and grain boundaries and hence, it can be concluded that PSN is indeed retarded by the dispersoids. It must be emphasized that the ODFs shown in Fig. 5 are so-called textures-by-number [13]. Consideration of the volume of the respective grains, in particular in the case of the large grains (Fig. 5a) would further favor these orientations in the final recrystallization textures (Fig. 1b).

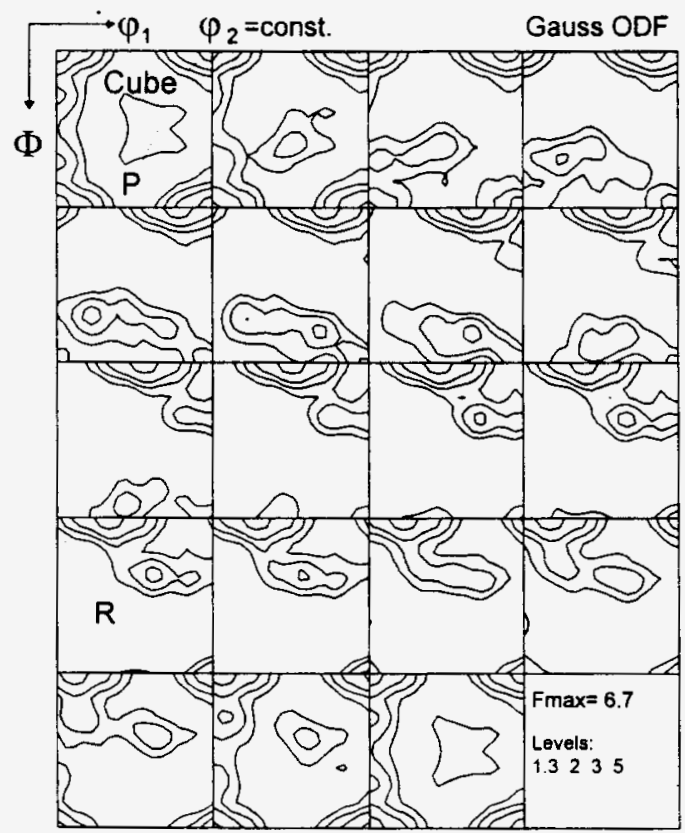

(a) large grains $(D>40 \mu \mathrm{m})$

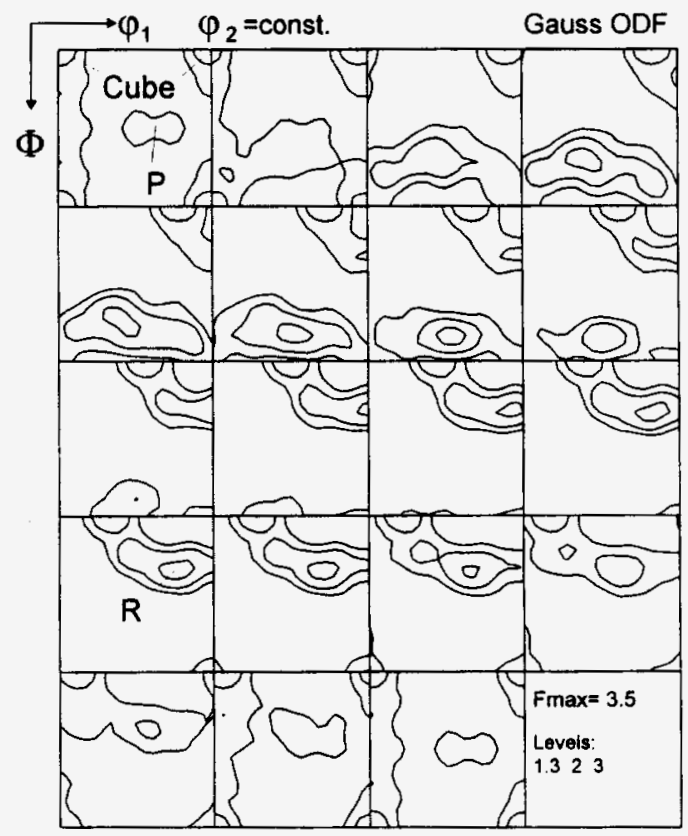

(b) small grains $(D<40 \mu m)$

Fig. 5: ODFs of the two different grain size classes. 
The ODF of the small grains (Fig. $5 b$ ) is very weak, in contrast, $f(g)_{\max } \approx 3$, comprising a strongly scattering cube-orientation as well as some intensities of the P- and the R-orientation. This ODF resembles the recrystallization texture of the samples in which PSN is dominating (e.g. Fig. 1a), which indicates that the small grains in sample A may nucleate by PSN. It must further be noted that during grain size measurements in two-dimensional sections large grains are frequently sectioned at positions far below or beyond there maximum size. This leads to an overestimation of their orientations in the ODF of the small grains (Fig. 5b) and may thus account for the surprisingly sharp cube- and R-orientations in this ODF as compared to Fig. la.

\section{Summary}

In was the aim of the present study to investigate the influence of dispersoids on the recrystallization in a ternary Al-Fe-Si model alloy. In dispersion-free samples, particle stimulated nucleation (PSN) occurring within the deformation zones around the large constituent particles gave rise to fine grained microstructures and very weak recrystallization textures with a characteristic rotation of the cube-orientation about ND and a minor P-component. In the presence of small finely dispersed precipitates - which may either already be present in the as-deformed state or may precipitate during the recrystallization anneal - pronounced cube- and R-recrystallization textures associated with larger grain sizes were obtained. This indicates that the dispersoids selectively suppress PSN but affect nucleation at cube-bands and grain boundaries to a much lesser extent. EBSD local texture analysis of different grain size classes in a recrystallized sample with a bimodal grain size distribution strongly supports this assumption.

Acknowledgments: Financial support by the US Department of Energy and by the Alexander von Humboldt-Foundation through a Feodor Lynen Research Fellowship is gratefully acknowledged.

\section{References}

1. F.J. Humphreys, Acta metall. 27 (1977) p. 1323.

2. R.D. Doherty and J.W. Martin, J. Inst. Metals 91 (1962/63) p. 332.

3. E. Hornbogen and U. Köster, in "Recrystallization of Metallic Materials" (F. Haeßner, ed.), Riederer-Verlag, Stuttgart (1978) p. 159.

4. O. Engler, J. Hirsch and K. Lücke, Acta metall. mater. 43 (1995) p.121.

5. H.E. Vatne, O. Engler and E. Nes, Mat. Sci. Tech. 13 (1997) p. 93.

6. O. Daaland and E. Nes, Acta mater. 44 (1996) p. 1413.

7. O. Engler and J. Hirsch, Mat. Sci. Forum 217-222 (1996) p. 479.

8. O. Engler, M. Tap, J. Hirsch and G. Gottstein, in "Proc. ICOTOM 11" (Z. Liang et al., eds.), International Academic Publishers, Beijing, China (1996) p. 405.

9. F.J. Humphreys, in "Proc. ICOTOM 11", as Ref. [8] (1996) p. 1191.

10. F.J. Humphreys and I. Brough, in "Proc. of ReX '96", ed. T.R. McNelley, ReX'96 International Advisory Board and Organizing Committee, Monterey, CA (1997) p. 315.

11. O. Engler, in "Proc. of ReX '96", as Ref. [10] (1997) p. 503.

12. O. Engler, Mat. Sci. Tech. 12 (1996) p. 859.

13. W. Bleck and H.J. Bunge, Acta metall. 29 (1981) p. 1401.

14. K. Ito, R. Musick and K. Lücke, Acta metall. $\underline{31}$ (1983) p. 2137.

15. J. Hjelen, R. Ørsund and E. Nes, Acta metall. mater. 41 (1993) p. 1377.

16. R.D. Doherty, K. Kashyap and S. Panchanadeeswaran, Acta metall. mater. 41 (1993) p. 3029.

17. B.L. Adams, S.I. Wright and K. Kunze, Metall. Trans. 24A (1993) p. 819. 
M98003005

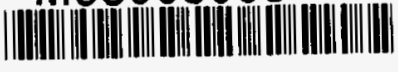

Report Number (14) $\angle A-4 R--97-4288$

subl. Date (11) 199712

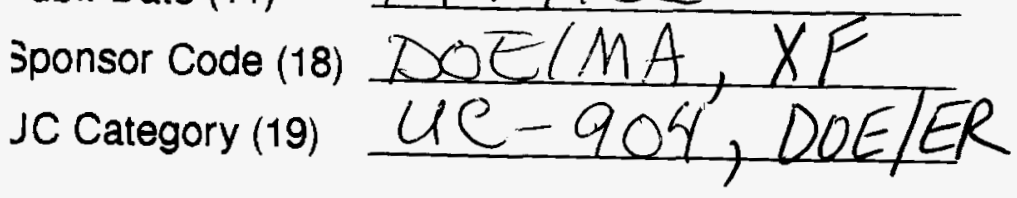

DOE 